\title{
A Generational Change: An Empirical Exploration of the Gen Y's Workplace Expectations
}

\author{
By Megan Nelson* \\ Kristian Braekkan
}

\begin{abstract}
The study was designed to empirically capture expectations of new job seekers and their perceived obligations and expectations as they enter a multigenerational workforce. Specifically, we utilized psychological contract theory to study differences in transactional and relational elements among graduating college seniors entering their first jobs, and the extent to which opportunistic careerism, expected tenure, and earning potentials influenced the contract formations. The sample $(n=405)$ were graduating seniors from a state university on the east coast of the United States and all belonged to Generation Y (also referred to as the Millennials). Contrary to existing theories, the results did not reveal that today's young job seekers exemplify "selfish" behaviors (i.e., expecting more from their future employer than they are willing to reciprocate). However, the data did suggest that individuals entering the workforce with an "opportunistic" mindset viewed their first job as a stepping stone for future employment and career opportunities, while those scoring lower on careerism endorsed greater loyalty and relational elements, which may not be that different from behaviors among other generations. Earning potential appeared to correlate with both types of psychological contracts (i.e., transactional and relational). However, we found that careerism did moderate and strengthen the relationship between earning potential and transactional contracts. A discussion of the results is included, in addition to limitations of the current study, and recommendations for future studies.
\end{abstract}

Keywords: Psychological contracts, Generation Y, Expectations, Obligations, Careerism

\section{Introduction}

Whenever a new generation enters the workforce, there is a lot of speculation about the effect they will have on workplace dynamics (Ferri-Reed, 2014). The latest generation to make their way into the ever-changing workplace is the Millennials, also referred to as Generation Y. While there are differing views on what exactly the age parameter is, the general consensus is that it includes anyone born between the years 1980 to 2000 (Fry, 2015). This puts the Millennials at an important age because they are the members of the population that are just entering college and beginning their professional careers. Just like past generations, it is anticipated that the Millennials will profoundly change the workplace and organization life.

With a new generation of laborers entering the workforce, comes a range of stereotypes and differing perspectives. Members of Generation $\mathrm{Y}$ are

\footnotetext{
* Bachelor's Candidate, Gustavus Adolphus College, USA.

${ }^{\dagger}$ Associate Professor, Gustavus Adolphus College, USA.
} 
perceived in both a positive light as well as a negative one. The overall reputation of Millennials is that they are tech savvy, they work well in group settings, and they are very confident. On the other hand, they are also thought of as having poor work ethic, unrealistic expectations, and a lack of respect for authority (Ferri-Reed, 2014). It is hard to tell at this point which of these stereotypes are in fact true, and which are unrealistic expectations placed on new employees with little to no past work experience.

One factor that plays a large role in determining what kind of worker an employee turns out to be and whether or not they remain working for a company is the psychological contract that is formed. A psychological contract is an unwritten contract that is formed between an employer and their employee during the hiring process (Rodwell and Gulyas, 2013) and later through organizational practices such as Human Resource policies (Rousseau, 1995). In short, expectations for both parties are set through these interrelated processes.

If expectations are not met, employees may experience what the literature refers to as a breach in the psychological contract. At this point, the productivity of the employee may decrease as they do not believe they are receiving sufficient compensation for the labor they are providing, or the employer becomes increasingly frustrated as the output of their employee does not meet their expectations (e.g., Coyle-Shapiro and Kessler, 2000; Herriott et al., 1997; Robinson and Morrison, 1995; Robinson and Rousseau, 1994; Rousseau and Tijoriwala, 1999; Turnley and Feldman, 2000). This interaction between subordinate and employer is an individual level perception of expectations and obligations and may change over time.

Although each individual employee receives and interprets expectations subjectively, previous research on psychological contracts has designated three types of contracts, transactional, relational, and balanced. Transactional contracts tend to be short-term, with highly specified terms. Further, these types of contracts are explicitly communicated, and normally require formal agreement by both parties. Relational contracts, however, are typically more open-ended, long term by nature, intangible, socio-emotional, implicit, and unlikely to involve actual agreement by both parties (Conway and Briner, 2005). The third type of contract, a balanced contract, is a mix of the two previous contracts. It is the middle ground that employees and employers attempt to reach through compromise that provides a balance between having a purely transactional contract, and purely relational contract. In order to successfully navigate the differences between generations within the workforce, management and employees alike should strive to achieve a balanced contract in order to maximize workplace satisfaction for both parties.

With previous generations, relational contracts were more common. There was a sense of loyalty and trust within the workplace. Now, contracts have turned more transactional. There is less trust, and far less loyalty between Millennials and their coworkers within the workplace. While it is difficult to pinpoint what has caused this shift, it is possible to draw some conclusions and 
attribute these changes to the economic conditions this generation was raised in, and how the recession of 2008 affected their economic outlook.

While a lot of research has been conducted in order to obtain a better idea of who the Millennials are, what we still do not know is why the youngest generation in the workforce is so different from previous generations. We know there has been speculation that the recession of 2008 played a role in shaping the Millennials in their formative years, but it is still unsure how much of a role it played, and how exactly it affected them. While each of these topics are important and essential for better understanding Generation Y, they also need to be explored to understand what the future holds for organizations and their employees. This paper seeks to examine expectations and perceived obligations among college educated members of Generation Y about to enter the workforce.

\section{Theory \& Hypotheses}

\section{Generational Differences}

Although it is difficult to narrow down an all-encompassing definition for the word "generation," this paper will utilize the following definition of what constitutes a generation, "all of people born and living at about the same time, regarded collectively." While this gives us a general idea of what the term generation encompasses, it is missing some key elements that describe how cultures define generations. While age group does play a factor, other factors such as societal conditions, significant world events, and demographic changes also play a large role in defining a generation. The distinctive differences between each generation can be both an advantage to an organization, and a disadvantage, as methods of management must be adjusted to accommodate for generational expectations and perceived obligations.

There are predominantly three generations in today's workforce, the Baby Boomers, Generation X, and the Millennials (Schweyer, 2015). The Baby Boomers are the oldest, with their birthdates ranging from 1946 to 1964 according to the U.S. Census Bureau (Colby and Ortman, 2014). This generation is defined by the ending of World War II. They were the children of those who fought and lived through the war, and the post-war economic boom contributed to the positive outlook of many Boomers. They grew up and worked in the economic growth and prosperity that followed. Due to the positive economic conditions of the Baby Boomer's generation, members of this generation were often able to become well established in their employing organizations, and they proved to be very loyal employees. The average number of jobs held by Baby Boomers throughout their entire working career is 11.3 (Colby and Ortman, 2015). Organizational practices developed in response to the scientific management school of the early twentieth century (e.g., Taylorism) and later the bureaucratic practices with incentives based polices inspired by the behavioral studies such as the Hawthorne experiments 
and the psychological influences by behavioral theorists such as Maslow and Helzberg. The lines between an employee and their superior were well defined, and a harsh, critical boss was expected (Korn and Feintzeig, 2014).

Generation X, while still distinct in its characteristics, is more difficult to define than the Baby Boomer generation. The general consensus regarding the age range of Generation Xers is that they were born between the years of 1960 to the early 1980s (Taylor and Gao, 2014). This generation is often overlooked and has not been analyzed nearly as much due to it being sandwiched between two very large generations that are distinctly different. Naturally, Generation X tends to fall in the middle of the two generations in many studies. For example, the Baby Boomer generation was predominantly Caucasian, with $72 \%$ of the population being of white, non-Hispanic descent. Generation X falls right in the middle at $61 \%$, and the Millennials rank at 57\% (Taylor and Gao, 2014). This trend remains consistent in every statistic analyzed in the study. Everything from median marriage age to political standing to social media use, Generation X fell right in the middle between the Boomers and the Millennials. In terms of the workplace, Generation $\mathrm{X}$ has proven to adequately navigate technology, and uphold formal relationships with their superiors, though not to the same extent as the Boomer generation.

The Millennials are generally defined as being born between the years 1980 and 2000. They have now become the largest generation in the workplace, surpassing even the Baby Boomers in numbers. As the most diverse, progressive, and technological generation, the Millennials have proven to be a challenge to today's organizations and their methods of management. The strict, formal management that worked with both the Boomers and Generation X may not work as well with the Millennials (Korn and Feintzeig, 2014).

One study performed by Ferri-Reed found that the traditionally formal relationship between a manager and their employee is not the norm among Millennials due to the close relationships the generation often formed with their superiors, including teachers and family members, during their formative years. This lack of formality has often been interpreted as a tendency for Millennials to disrespect authority rather than simply a changing dynamic (Ferri-Reed, 2014). This divide between Millennials and their superiors due to misinterpreted stereotypes, along with their dissatisfaction with traditional management styles has contributed to high turnover rates. One of the main challenges facing organizations today is how to overcome these stereotypes and placate this generation in order to lower the high rates of turnover that many companies are currently experiencing.

It is easy to recognize that there are distinct differences between each generation, but the Millennials have proven to be vastly different than every preceding generation. Rentz (2015) evaluated the extent to which employees under the age of 31 ranked in various categories compared to previous generations of employees when they were of the same age group. These categories included prompts such as "take initiative," "contribute ideas," and "efficient," where in nearly each category evaluated the Millennials surpassed 
the expectations of management, and surpassed the performance of previous generations. This study exhibits how despite the negative stereotypes that surround Millennials, they in fact do demonstrate high performance within the workplace, and exceed the expectations of upper management.

With multiple generations with very different values and personalities in the workplace, it is important that the characteristics and expectations of each generation are defined. Without this knowledge, it would be very difficult to effectively manage multigenerational organizations. With more knowledge regarding the different generations, management can evaluate which techniques to use with each generation to promote higher employee retention and overall workplace satisfaction. In order to understand the employer/employee dynamics, the psychological contract construct may prove to be a good tool for understanding the expectations and perceived obligations the Millennials hold as they enter the workforce.

\section{Psychological Contracts}

A psychological contract is a social exchange in which a perception is formed regarding workplace relationships, generally between an employee and their employer (Rousseau, 1995). It is an unspoken exchange that often occurs at the time of hire that establishes the perceived promises and expectations of both members of the contract (DelCampo, 2007). These promises and expectations can be anything ranging from employee benefits and pay to output and productivity. Because the contract is formed by the individual, each person's psychological contract will be unique (Rousseau, 1995).

Due to the different desires and expectations of individuals regarding their psychological contract, different types of contracts can be formed. The two types of contracts that are most common among the workforce are relational (the employment relationship extends beyond the formally defined job expectations) and transactional (the employment relationship is narrowly viewed as a pure economic transaction) (Braekkan, 2012). By better understanding the different types of contracts, managers and employees alike can benefit due to increased knowledge about the expectations and attitudes of the other party. A relational contract is defined by personal relationships, loyalty, and faith in the organization or individual (Rousseau, 1990; 1995). Transactional relationships instead focus more on the actual rewards received or output produced. It is more of a quantitative, impersonal measure than a relational contract. As mentioned previously, balanced contracts consist of a combination of both transactional and relational contracts. It is up to the employer and the employee to establish a compromise between the two, as often times, especially among Millennials, employees wish to give in a transactional manner and receive relationally. By forming a balanced contract, workplaces can attempt to establish more loyalty between an employee and the employer, while also maintaining the formality that accompanies a transactional relationship. 
One of the main factors that determine whether or not a psychological contract will be fulfilled or whether a breach will occur depends on if the expectations and obligations of the employee and employer align. If the expectations of the manager are met by the performance of the employee, then the contract is fulfilled. If the expectations of the employee regarding their benefits and work environment are met, then their end of the contract has also been met. Often times though, the expectations of one party do not meet what the other party feels is an obligation, which can cause tension on the contract. The overall health of the relationship between an employee and the organization is dependent on these expectations and obligations, and their fulfillment.

Due to the unspoken nature of the contract, it can be hard for both parties to understand the expectations of the other, which can lead to either the fulfillment or a breach of the contract. If the contract is indeed fulfilled by both parties, the result is increased employee retention and overall satisfaction, and employer satisfaction as well. The employee feels as though the promises that were made upon hire have been upheld, and the employer feels as though the employee is meeting or exceeding the expectations that were formed regarding productive output. This is the ideal result of a psychological contract.

The other result of the formation of a psychological contract is a breach. A breach occurs when the perceived promises made to either party are not fulfilled. When a breach occurs, the party that feels as though they have been wronged performs a "cognitive comparison of what has been promised and received" (Braekkan, 2012). This is the process of realizing the contract has not been fulfilled.

A violation is the result of a psychological contract breach. It results in an emotional response, which can range from anger to disappointment to other feelings of emotional distress and resentment (Conway and Briner, 2005). Due to the negative emotions and responses that can result from a contract breach, it is important for an organization to understand and prevent contract violations in order to prevent the consequences associated with a violation.

When a violation occurs, not only does the wronged party suffer emotionally, it can also affect the organization as a whole. If it is the employee who suffers from the breach, it can lead to decreased productivity, which in turn results in decreased output for the company. This can also lead to decreased employee retention, as an employee may seek career opportunities elsewhere if they do not feel they have an obligation to the company. If it is the employer who feels a breach has occurred, it can lead to a worsened relationship with their employee, possible termination, and overall dissatisfaction within the workplace.

While psychological contracts are dependent upon the perceived promises made at the point of hire, there are other factors that affect the formation of these contracts. The workplace has been seeing shifts in the types of contracts that have been formed, and the way interactions between employees and employers occur. Societal changes and shifts can have a major impact on these contracts. For example, the shift from face-to-face communication to 
impersonal exchanges via technology has played a major role in the shift of psychological contracts being more transactional rather than relational. There is less of a bond formed between an employee and their employer, and thus less loyalty within an organization. As loyalty has increasingly become less prevalent in the workplace, careerism has become the norm (Rousseau, 1990). Jobs are now seen as a stepping-stone to further one's career rather than a longterm prospect. With college students being told they will hold multiple jobs throughout the course of their career, and with increasing importance being placed on external mobility (Rousseau, 1990), it is easy to see why employee retention has become so difficult for many companies.

\section{Generational Differences and Psychological Contracts}

As discussed previously, the three generations that currently dominate the workplace have distinctly different characteristics. These differences between generations help explain the shift in psychological contracts, and the everchanging workplace dynamic. The rise of the use of technology for communicating instead of face-to-face interactions could be a major contributing factor in the shift from relational psychological contracts to transactional. Another cause of this shift could be due to the changes that occurred in the workplace both during and after the recession of 2008. Longterm bonds were broken between employees and their employers, which contributed to less loyalty and overall satisfaction in the workplace. Many of the workers entering the workplace displayed signs of cynicism toward both the economy as well as toward businesses as a whole. This lack of trust and loyalty in the workplace has proven to be a challenge to managers, as employee retention has become a serious issue, and relations tend to remain impersonal (Braekkan, 2012).

For many managers, the shifts in the overall workplace attitude and the types of contracts that are formed have proven to be a serious challenge. Gaining employee trust and creating workplace satisfaction has become an issue, which in turn decreases employee retention. It is in the interest of the organization to increase employee satisfaction and retention, because it is costly in terms of both fiscal resources as well as to the reputation of the company if there are high turnover rates. The challenge to managers is to evaluate the workplace, better understand the wants and demands of their employees, and alter their management style to increase overall satisfaction and retention (Richardson, 2014).

As technology plays an increasingly important role in society, it is important to evaluate how these advancements are affecting the workplace, and how to adjust to the changes. A recent survey asked managers about how they have addressed changes in the workplace. One prompt stated, "I use technology more frequently with Millennials to help keep them engaged," to which $59.38 \%$ of respondents said they agree, and an additional $28.13 \%$ said they strongly agree. (Ferri-Reed, 2014). These statistics demonstrate just how 
important technology has become in the workplace, and how it is becoming necessary for managers to adapt in order to better engage with their employees.

According to the U.S. Census Bureau, the median tenure is 1.8 years among people ages 18-35 (Colby and Ortman, 2015). With these statistics in mind, employers have come to realize that changes must be made in order to make the workplace more appealing to the younger generation. Millennials have proven to be very comfortable with the use of technology, so in order to cater to their strengths, managers have begun to realize the importance of incorporating more technology into the workplace. Companies such as Apple and Autodesk have noticed this trend, and they have implemented a system of employee development and training that includes an online gamification platform to better engage these employees rather than attempt to train them in more conventional ways, such as with meetings and lecturing (Ware, 2014). Other companies such as Google, Entepath, and NBC Bank have also found different ways to incorporate technology into the workplace to improve communication and hopefully the overall retention of employees. With face-toface communication becoming less common, and communication via email and telephone rising, it is important for management to understand these changes in order to better engage their employees.

Another factor that has contributed to decreased employee loyalty and retention is the recession of 2008. While it began over 7 years ago, the recession still affects the lives of people today, especially in terms of employee loyalty and overall optimism toward the workplace. There was not one single cause of the recession; rather it was a buildup of many events and practices that led to the eventual collapse of the United States economy, and in turn the world economy. One of the main causes of the recession was the practice of risky investments (McNally, 2011). Investments were made that eventually could not be paid back, especially within the housing market. Mortgages were granted to people who could not afford them, which resulted in mass foreclosures. These investments were made with intangible money, money the banks did not actually have. Investments of this sort became increasingly popular following the U.S. deviation from the Gold Standard that was established at Bretton Woods. Once money was no longer tied to a commodity, risky investments with intangible money became increasingly possible (Kiely, 2005).

One of the main consequences of the 2008 recession was the transformation of how private debt turned public. The working class had to pay for the risky investments made by big businesses, which resulted in what has been named the "Decade of Pain." (McNally, 2011). Many of the members of the working class were negatively affected as a result. Many people were laid off during this time, and in order to reduce deficit spending to try to put money back into the economy, many lower class benefits and aid programs were cut, despite the fact that those programs were needed the most (McNally, 2011). These consequences resulted in widespread financial hardship as the unemployment rate steadily began to rise beginning in 2008, and peaked at $10.0 \%$ in October of 2009 (Colby and Ortman, 2015). While the economy has slowly improved, the implications of the recession impacted young families 
getting established and raising children during the early years of the $21^{\text {st }}$ century.

Following the recession, companies experienced a shift in employee attitudes and overall loyalty. According to a study performed in Canada in $2009,22 \%$ of employees overall felt less loyalty to their employer as a result of the recession, $31 \%$ felt less loyal in organizations where salaries were frozen, and $36 \%$ of employees felt less loyal in organizations where fellow employees had been laid off (Ipsos-Reid, 2009). These statistics demonstrate that there is a direct correlation between workplace conditions and overall employee loyalty and satisfaction. With decreased loyalty, the potential for higher rates of employee turnover increases. These changes in the attitudes of employees is representative of what occurs when there is a breach in the psychological contract between an organization and an employee, therefore warranting an investigation of how contract content impact workplace attitudes among those about to enter the workplace in the wake of these major economic changes that have taken place.

Transactional contracts assume clearly defined employer/employee expectations (employer to employee) and obligations (employee to employer), and no implied expectations that the parties will contribute beyond specified terms. Relational contacts, on the other hand, assume that the employer is concerned about the employee's well-being in return for contributions on assignments that go beyond previous arrangements and experiences (Tsui et al., 1997). Psychological contracts are subjective as no formal agreements about expectations and obligations are reached between the parties. Hence, all expectations and obligations are therefore "perceived" expectations and obligations. This is particularly important to recognize in this study as the theory focuses on a generation that is only starting out in their careers. Consistent with Rousseau's (1990) and Braekkan andTunheim's (2013) findings, we expect to find that perceptions of employee and employer obligations will be inter-related:

Hla: Transactional contract expectations will correlate positively with transactional contract obligations.

H1b: Relational contract expectations will correlate positively with relational contract obligations.

With the natural uncertainty associated with entering the workplace, particularly in a very competitive post-recession job market, new hires may not, however, view their first job as one that they will stay with for an extended period of time. Graduating college seniors often expect that they will have multiple jobs and possibly multiple careers. It would therefore be natural to assume that some new hires will seek out employment opportunities with future external mobility in mind, which in literature is referred to as careerism (Rousseau, 1990). Such career behaviors exemplify themselves as situations where employees view their employment with a particular organization as a stepping-stone to better jobs elsewhere. Consistent with previous research (e.g. 
Braekkan and Tunheim, 2013; Rousseau, 1990) it would be natural that young job seekers hold transactional views of their employment since they perceive few obligations to exist between themselves and their future employers. Hence, we hypothesize:

H2a: Careerism will correlate positively with transactional contract expectations and obligations.

H2b: Careerism will correlate negatively with relational contract expectations and obligations.

Previous literature suggests that employees with relational contracts are more willing to adjust to new and challenging performance requirements and embrace opportunities for career development provided by the employer such as training and development (Conway and Briner, 2005; Millward and Hopkins, 1998; Rousseau, 1995). Since they also tend to view work arrangements as open-ended, it would be natural to assume such employees would see the employment relationship as ongoing and dynamic as they are promised opportunities for professional and personal growth, in contrast to those with transactional expectations. We therefore hypothesize:

H3a: Expected tenure will be positively correlated with relational contracts, and negatively correlated with transactional contracts.

H3b: Skill utilization will be positively correlated with relational contracts, and negatively correlated with transactional contracts.

H3c: Earning potential will be positively correlated with transactional contracts, and negatively correlated with relational contracts.

The dynamic nature of relational contracts stands in stark contrast with the "black and white" view of the transactional contract. While entering the workplace for the first time under high uncertainty in the post-financial crisis era, it is not unlikely that new hires view their first job as one that they will not stay with for an extended period of time. It would therefore be natural to assume that some new hires will seek out employment opportunities with future external mobility in mind. Rousseau (1990) suggested that employees exhibiting such behaviors are adopting a transactional view of their employment since they perceive few obligations to exist between themselves and the employing organization. Braekkan and Tunheim (2012) additionally found that careerism was strongly correlated with transactional contract formation. We therefore expect that those motivated by earning potential (the economic component of the employment exchange) will endorse even stronger transactional elements in the presence of high careerism. Hence, we hypothesize:

H4: Careerism will moderate and strengthen the relationship between earning potential and transactional contracts. 


\section{Methodology}

\section{Sample and Procedure}

The participants in this study consisted of 405 graduating seniors from a state university on the east coast of the United States. All subjects had secured employment following graduation and they were currently enrolled in their last semester of course-work when the collection of data took place. The subjects were told that the study aimed to better understand the employer/employee relationship. Four hundred and fifty surveys (including items identifying transactional and relational contract items, what the respondents expected from their employer, such as opportunities for growth, pay, paid leave, etc., items regarding opportunistic behaviors (i.e., careerism), and expected tenure with the employing organization) were distributed to students who had identified themselves as "employed following graduation" and 405 (response rate $=90 \%$ ) complete and useable surveys were returned from the students. Of the respondents, 47 percent were female and 53 percent were male. The mean age was approximately 20.7 years $(\mathrm{SD}=1.5)$.

\section{Instruments}

Psychological Contract Content. Psychological contract content was measured with the 18-item scale used by Raja, Johns, and Ntalianis (2004), which is an abbreviated version of Millward and Hopkins' (1998) 33-item Psychological Contract Scale. For each item, respondents were asked to indicate their obligations and expectations to their organization. Responses were made on a 7-point scale ranging from 1=strongly disagree to $7=$ strongly agree. Cronbach's $\alpha$ for this scale was .87 .

Employer/Employee Obligations. Consistent with Rousseau (1990), the respondents were asked to indicate what they believed to be their obligations to their future employer and the employer's obligations to them. Employee obligations were measured with eight items using a 1-7 scale (from "strongly disagree" to "strongly agree"), and employer obligations were measured with seven items using a 1-7 scale (from "strongly disagree" to "strongly agree"). The items yield scale reliabilities of 0.82 and 0.79 respectively.

Careerism. The questionnaire contained five questions measuring expectations about changing employers many times during one's career. These questions were identical to those utilized by Rousseau (1990), and it utilized a 1-7 scale (from "strongly disagree" to "strongly agree"). Items included: (1) I took this job as a stepping-stone to a better job with another organization, (2) I expect to work for a variety of different organizations in my career, (3) I do not expect to change organizations often during my career (reverse scoring), (4) there are many career opportunities I expect to explore after I leave my present employers, and (5) I am really looking for an organization to spend my entire career with (reverse scoring). The items yield an alpha reliability of 0.78 . 
Expected Tenure. The respondents were asked to indicate how long they expect to remain with their first organization using the following scale: (0) less than a year (1) 1 year (2) 2 years (3) 3 years (4) 4 years (5) 5 years or more.

Skill Utilization/Development and Earning Potential. Items measuring the importance of skill utilization/development and earning potential were adapted from the goal orientation instrument developed by Van Yperen and Janssen (2004). Responses were measured using a 1-7 scale (from "strongly disagree" to "strongly agree"). All items are included in Appendix B. The items yield scale reliabilities of 0.88 and 0.92 respectively.

Gender. Respondents' gender were recorded and dummy-coded $(0=$ male, $1=$ female) in order to control for the possibility that there could be gender differences.

\section{Results}

The zero-order correlations in this study are provided in Table 1 below. The correlations were calculated in order to test hypotheses 1-4.

Table 1. Zero-order Correlations

\begin{tabular}{llllllll}
\hline & & & & & & \\
& 1 & 2 & 3 & 4 & 5 & 6 & 7 \\
\hline $\begin{array}{l}\text { Employer Contract } \\
\text { (1) Transactional }\end{array}$ & & & & & & & \\
(2) Relational & 0.04 & & & & & & \\
& & & & & & & \\
Employee Contract & & & & & & & \\
(3) Transactional & $0.39 *$ & 0.05 & & & & & \\
(4) Relational & 0.09 & $0.49^{*}$ & 0.07 & & & & \\
(5) Careerism & $0.33^{*}$ & $-0.38^{*}$ & $0.41^{*}$ & $-0.36^{*}$ & & & \\
(6) Expected tenure & 0.03 & $0.13^{*}$ & 0.07 & $0.26^{*}$ & $-0.56^{*}$ & $0.18^{*}$ & \\
(7) Skill utilization & $0.33^{*}$ & $0.42^{*}$ & $0.25^{*}$ & $0.47^{*}$ & 0.06 & 0.07 & 0.06 \\
(8) Earning potential & $0.42^{*}$ & $0.39^{*}$ & $0.35^{*}$ & $0.30^{*}$ & 0.05 & $0.18^{*}$ & -0.09 \\
* $<0.05$ & & & & & & &
\end{tabular}

Hypothesis 1a proposed that transactional contract expectations would correlate positively with transactional contract obligations. The results revealed a positive and statistically significant relationship between employer and employee transactional contract obligations $(r=0.39, \mathrm{p}<0.05)$. Similarly, hypothesis $1 \mathrm{~b}$ proposed that relational contract expectations would correlate positively with relational contract obligations between employer and employee with respect to contract perceived obligations and expectations, which was confirmed by the results $(\mathrm{r}=0.49, \mathrm{p}<0.05)$. Thus, both hypotheses $1 \mathrm{a}$ and $1 \mathrm{~b}$ were supported.

Hypotheses $2 \mathrm{a}$ and $2 \mathrm{~b}$ proposed that careerism would correlate positively with transactional contract expectations and obligations (2a), but negatively with relational contract expectations and obligations (2b). Consistent with the hypotheses, careerism correlated positively with both transactional expectations $(r=0.33, p<0.05)$ and obligations $(r=0.49, p<0.05)$, but negatively 
with relational expectations $(\mathrm{r}=-0.38, \mathrm{p}<0.05)$ and obligations $(\mathrm{r}=-0.36$, $\mathrm{p}<0.05)$. Thus, both hypotheses $2 \mathrm{a}$ and $2 \mathrm{~b}$ were supported.

Hypothesis 3a suggested that expected tenure would be positively correlated with relational contracts, and negatively correlated with transactional contracts. Similarly hypothesis $3 \mathrm{~b}$ suggested that skill utilization would also be positively correlated with relational contracts, and negatively correlated with transactional contracts. Contrary, hypothesis $3 \mathrm{c}$ suggested that earning potential would be positively correlated with transactional contracts, and negatively correlated with relational contracts. Consistent with hypothesis $3 \mathrm{a}$, expected tenure correlated positively with relational contract expectations $(\mathrm{r}=0.13, \mathrm{p}<0.05)$ and obligations $(\mathrm{r}=0.26, \mathrm{p}<0.05)$, but negatively with transactional obligations $(\mathrm{r}=-0.26$, $\mathrm{p}<0.05)$. No significant relationship existed between expected tenure and transactional expectations. Interestingly, skill utilization correlated significantly and positively with both relational expectations $(r=0.42, \mathrm{p}<0.05)$ and obligations $(\mathrm{r}=0.47, \mathrm{p}<0.05)$ and transactional expectations $(\mathrm{r}=0.33, \mathrm{p}<0.05)$ and obligations $(r=0.25, p<0.05)$. Hypothesis $3 c$ suggested that earning potential would be positively correlated with transactional contracts, and negatively correlated with relational contracts. Similarly, to hypothesis $3 b$, the results revealed that this element correlated with both transactional and relational contracts. Earning potential correlated significantly and positively with relational expectations $(\mathrm{r}=0.39, \mathrm{p}<0.05)$ and obligations $(\mathrm{r}=0.30, \mathrm{p}<0.05)$ and transactional expectations $(r=0.42, \mathrm{p}<0.05)$ and obligations $(\mathrm{r}=0.35, \mathrm{p}<0.05)$. Thus, hypotheses $3 \mathrm{a}, 3 \mathrm{~b}$, and $3 \mathrm{c}$ were only partially supported.

Hypothesis 4 suggested that careerism would moderate and strengthen the relationship between earning potential and transactional expectations. With respect to this hypothesis, multiple regression analysis was used. In order to assess the interaction effect, a moderated regression was performed, consistent with Aiken and West (1991), where the variables were centered at their means in order to make the results more interpretable. As shown in Table 2 below, there was a significant interaction between careerism and earning potential in predicting transactional expectations $(\beta=-0.40, p<.0 .05)$. Thus, Hypothesis 5 was supported. Although used as a control variable, gender differences were not statistically significant.

Table 2. Moderated Regression Analyses

\begin{tabular}{lll} 
Dependent Variable & $\begin{array}{l}\text { Transactional } \\
\text { Contract Expectations }\end{array}$ & $\begin{array}{l}\text { Transactional } \\
\text { Contract Obligations }\end{array}$ \\
\hline $\begin{array}{l}\text { Control variables } \\
\text { Gender }\end{array}$ & -.03 & -.03 \\
Main effects & & $.42^{*}$ \\
Careerism & $.39 *$ & $.31^{*}$ \\
Earnings & $.44^{*}$ & .44 \\
Interactions & .40 & $58.39 *$ \\
F & $63.07^{*}$ & .50 \\
Overall R & .59 & .47 \\
Adjusted $\mathrm{R}^{2}$ & .55 &
\end{tabular}

$* \mathrm{p}<.05$ Notes. Two-tailed hypothesis test.

\# Goal = earnings $\mathrm{x}$ skills 
As shown in Table 2 and illustrated in Figure 1 below, transactional contract expectations vary across levels of careerism. As Figure 1 illustrates, the positive relationship between earning potential and relational expectations was particularly strong among respondents high on careerism. The same procedure was followed regarding transactional obligations, with very similar results as indicated in the second column of Table 2 and illustrated in Figure 2.

Figure 1. Slope Analysis - Careerism and Earning Potential on Transactional Expectations

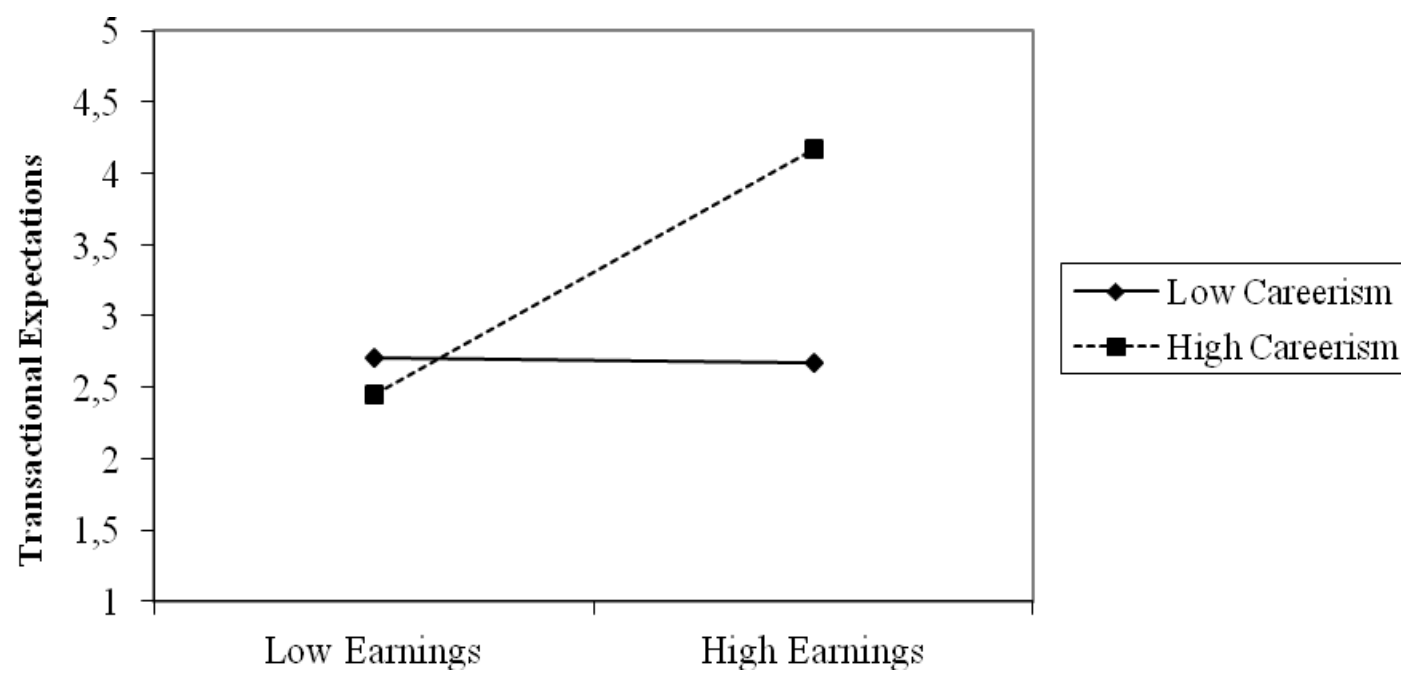

Figure 2:.Slope Analysis - Careerism and Earning Potential on Transactional Obligations

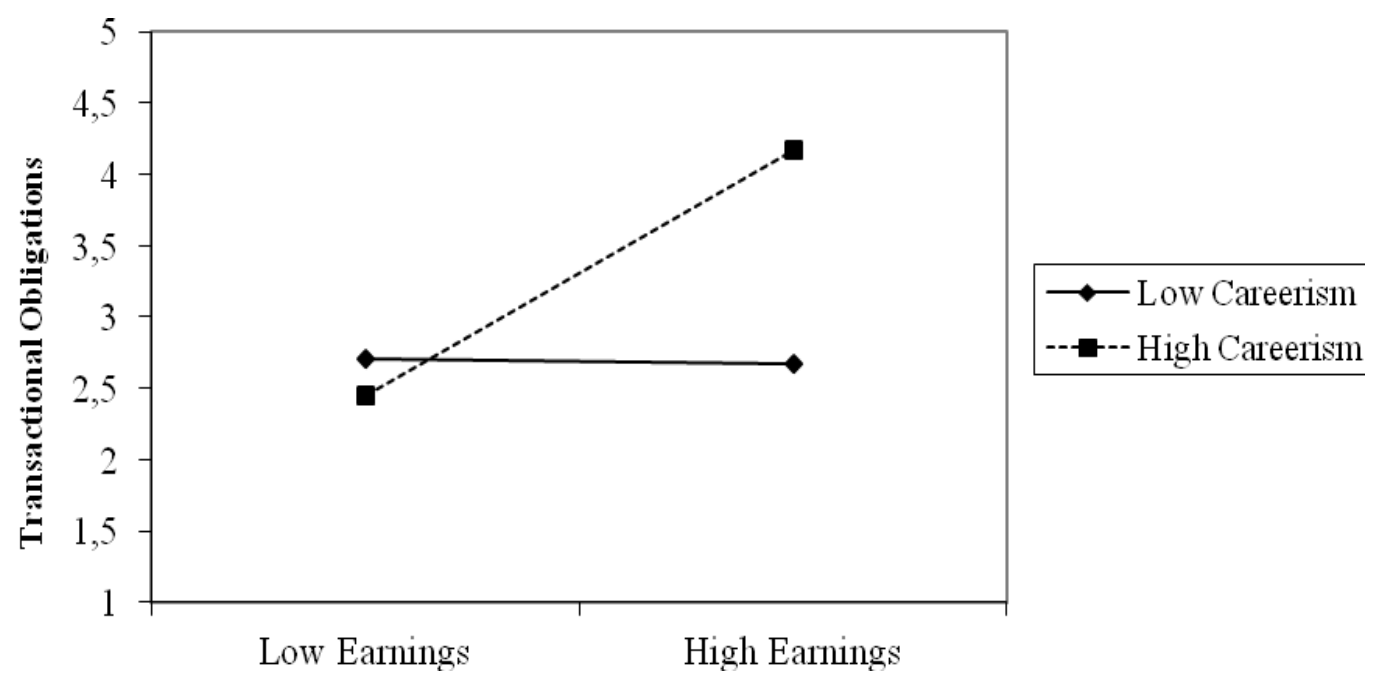




\section{Discussion}

The purpose of this study was to examine the expectations of new job seekers and their perceived obligations and expectations as they enter a multigenerational workforce. The social and technological conditions in which they have been raised have been quite different than those managing today's organizations. Further, the graduating college seniors in this sample were also facing very competitive job markets. The results were quite interesting from a number of different perspectives. We have summarized the main findings into five major categories.

First, we found that transactional contract expectations did indeed correlate positively with transactional contract obligations as the results revealed a positive and statistically significant relationship between employer and employee transactional contract obligations. This suggests that the individuals who view their employment with their first post-collegiate full-time job as a pure economic exchange did not expect to give more than what is expected to the employer, nor did they expect the employer to go above and beyond in return. Similarly, those endorsing relational contract expectations also endorsed similar obligations in return. This suggests that regardless of contract type, today's young job seekers did not reveal any "selfish" behavior where they expect more from their future employer than they are willing to reciprocate.

Second, we found that careerism did correlate positively with transactional contract expectations and obligations and negatively with relational contract expectations and obligations. This suggests that individuals entering the workforce with an "opportunistic" mindset will most likely see the first job as a stepping stone for future employment and career opportunities, while greater loyalty and relational elements can be expected from those lower on careerism. This further suggests that transactional contracts can be associated with careerism as a mindset among a subset of the Gen Yers in our sample, and may not be all that different from opportunistic behaviors among other groups.

Third, we found that expected tenure was positively correlated with relational contract expectations but not with transactional elements (neither positively nor negatively). Surprisingly, skill utilization/development correlated significantly and positively with both relational expectations and obligations and transactional expectations and obligations. It was not surprising that those with relational contract expectations actively sought out opportunities for skill development. However, we did not expect those with transactional expectations to desire the same opportunities. This inconsistency with the early findings of this group, where they did not expect anything above and beyond the economic elements of their contracts, may reveal that this group of young job seekers value opportunities for skill developments beyond their college education as part of their career oriented mindsets. Hence, they look for opportunities in the workplace to make themselves more competitive.

Fourth, we found that earning potential correlated with both transactional and relational contracts (despite our hypothesis, which suggested that earnings 
would correlate negatively with relational contracts). Earning potential in their future jobs correlated significantly and positively with relational expectations and obligations and transactional expectations and obligations. Given the high cost of education in the United States today and the competitive job markets they are entering, it is understandable that earnings were endorsed as universally important among the sample subjects, regardless of contract content.

Fifth, we found that careerism did moderate and strengthen the relationship between earning potential and transactional contracts, which is interesting given the findings above. This suggests that those motivated by earning potential endorsed even stronger transactional elements in the presence of high careerism. This tells us that the opportunistic elements in an individual interacts with their desire for higher earnings and thereby strengthen the economic component of the employment exchange. Hence, the "selfishness" the Millennials have been accused of appears to present itself most strongly among those motivated by earnings and have career ambitions that manifest themselves through opportunistic job seeking and employment.

From a managerial standpoint, the findings in this study have several practical implications. First, it is important for organizations to recognize that several entities contribute to the creation, such as recruiters, managers, and coworkers (Rousseau, 1995). Specifically, explicit promises are communicated prior to hiring, such as expressions of organizational policies (Ho et al., 2006), or post-hire when managers and supervisors communicate promises of pay raises and promotions to subordinates, during times of turmoil or change (e.g., downsizing and layoffs; Rust et al., 2005). Additionally, workers develop and possess pre-employment beliefs based on implicit promises that initiate the desire to be employed with a specific organization (Rousseau, 1995) in addition to promises realized through their perception of interpersonal treatment from their employers once they are hired (Saunders and Thornhill, 2006).

Second, perceived obligations to the employer as identified by endorsing relational psychological contract content, is associated with a desire to spend time with an organization. Considering the high cost associated with turnover, managers should be aware that individuals with relational contracts are more likely to stay with an employer for an extended period of time than someone with a transactional contract. Additionally, the relatively strong and negative relationship between careerism and relational contracts suggest that being "opportunistic" in the employment relationship is less likely to be observed in someone with a relational contract.

We did not find that Millennials revealed obligations to a company were atypically transaction based and that they desired to receive relationally. However, in order to smooth over differences between generations and the decrease of loyalty and trust that has become the trend in the workplace, organizations may need to adjust to the different skills and interests provided by these younger generations. The first challenge that faces organizations is the stereotypes that have been established regarding Millennials. In order to avoid 
beginning the working relationship between Millennials and their superiors with negative perceptions and animosity, it is important for organizations to understand the stereotypes of this generation, and why they have been formulated. By understanding who Generation $\mathrm{Y}$ is, organizations can create realistic expectations for new employees and change their management style to better cater to them.

\section{Limitations and Future Studies}

Our study has added to our understanding of the changes that are taking place in the workforce with respect to generational adaptations and new employees' expectations and perceived obligations. The design of this study, however, is also a limitation that future studies should seek to address. The data was collected cross-sectionally through self-reports so results could be biased due to common-method variance and percept-percept inflation. Further, the study did not address causality due to its use of cross-sectional data, so there is a possibility that those most aware of the employment obligations/ promises are also less likely to endorse careerism. Future research would benefit from longitudinal data and/or data from multiple sources, such as managers or peers. It would also be interesting to examine whether there are industry differences, or differences between public and private firms, or between for profit organizations and government or not for profit organizations. Additionally, although the samples were of moderate sizes, future studies should use larger samples.

\section{References}

Aiken LS, West SG (1991) Multiple Regression: Testing and Interpreting Interactions. Newbury Park, CA: Sage.

Braekkan KF (2012) High performance work systems and psychological contract violations. Journal of Managerial Issues 24(3): 277-292.

Braekkan KF, Tunheim KA (2013) Psychological contracts, careerism, and goal orientations. International Journal of Organization Theory and Behavior 16(2): 245-263.

Colby SL, Ortman JM (2014) The baby boom cohort in the United States: 2012 to 2060 Washington, DC: US Census Bureau.

Colby SL, Ortman JM (2015) Projections of the size and composition of the U.S. population: 2014-2060. Washington, DC: US Census Bureau.

Conway N, Briner RB (2005) Understanding Psychological Contracts at Work: A Critical Evaluation of Theory and Research. Oxford, Great Britain: Oxford University Press.

Coyle-Shapiro J, Kessler I (2000) Consequences of the psychological contract for employment relationship: A large-scale survey. Journal of Management Studies 37(7): 903-930.

DelCampo RG (2007) Understanding the Psychological Contract: a Direction for the Future. Management Research News 30(6): 432-440.

Ferri-Reed J (2014) Leading a Multi-Generational Workforce: Millennializing the 
workplace. The Journal for Quality and Participation 36(4): 13-14.

Fry R (2015) Millennials surpass Gen Xers as the largest generation in US labor force. Available at: http://www.pewresearch.org/fact-tank/2015/05/11/millennial s-surpass-gen-xers-as-the-largest-generation-in-u-s-labor-force/

Herriott P, Manning W, and Kidd JM (1997) The content of the psychological contract. British Journal of Management 8(2): 151-162.

Ho VT, Rousseau DM, and Levesque LL (2006) Social networks and the psychological contract: Structural holes, cohesive ties, and beliefs regarding employer obligations. Human Relations 59(4): 459-481.

Ipsos-Reid Research Center (2009) Loyalty Satisfaction. Available at: http://www. ipsos-na.com/news-polls/pressrelease. aspx? $\mathrm{id}=4452$

Kiely, R. (2005) The Clash of Globalisations: Neo-Liberalism, The Third Way and Anti-Globalisation. The Netherlands: Brill.

Korn M, Feintzeig R (2014) Is the hard-nosed boss obsolete? Available at: http:// www.wsj.com/articles/SB10001424052702303749904579578483510931384

McNally D (2011) Global slump: The economics and politics of crisis and resistance. Oakland, CA: PM Press.

Millward LJ, Hopkins LJ (1998) Organizational commitment and the psychological contract. Journal of Social and Applied Psychology 28(16): 16-31.

Raja U, Johns G, and Ntalianis F (2004) The impact of personality on psychological contracts. Academy of Management Journal 47(3): 350-67.

Rentz KC (2015) Beyond the generational stereotypes: A study of US Generation Y employees in context. Business and Professional Communication Quarterly 78(2): 136-166.

Richardson FW (2014) Enhancing Strategies to Improve Workplace Performance Doctoral dissertation. Available at: http://scholarworks.waldenu.edu/cgi/view content.cgi? article $=1105 \&$ context $=$ dissertations

Robinson SL, Morrison EW (1995) Psychological Contracts and OCB: The Effect of Unfulfilled Obligations on Civic Virtue Behaviour. Journal of Organizational Behavior 16(3): 289-298.

Robinson SL, Rousseau DM (1994) Violating the psychological contract: Not the exception, but the norm. Journal of Organizational Behavior 15(3): 245-259.

Rodwel J, Gulyas A (2013) The impact of the psychological contract, justice and individual differences: nurses take it personally when employers break promises. Journal of Advanced Nursing 69(12): 2774-2785.

Rousseau DM (1990) New hire perceptions of their own and their employer's obligations. Journal of organizational behavior 11(5): 389-400.

Rousseau DM (1995) Psychological Contracts in Organizations: Understanding Written and Unwritten Agreements. Thousand Oaks, CA: Sage Publications.

Rousseau DM, Tijoriwala SA (1999) What makes a good reason to change? Motivated reasoning and social accounts in organizational change. Journal of Applied Psychology 84(4): 514-528.

Rust KG, McKinley W, and Moon-Kyungpook, G, et al. (2005) Ideological foundations of perceived contract breach associated with downsizing: An empirical investigation. Journal of Leadership and Organizational Studies 12(1): 37-52.

Saunders MNK, Thornhill A (2006) Forced employment contract change and the psychological contract. Employee Relations 28(5): 449-467.

Schweyer A (2015) Generations in the workforce \& marketplace: Preferences in rewards, recognition \& incentives. Available at: http://theirf.org/research/genera tions-in-theworkforce-marketplacepreferences-in-rewards-recognition-incenti ves/1427/ 
Taylor P, Gao G (2015) Generation X: America's Neglected 'Middle Child, Pew Research Center. Available at: www.pewresearch.org/fact-tank/2014/06/05/gene ration- $\mathrm{x}$-americas-neglected-middle-child.

Tsui AS, Pearce JL, and Porter LW et al. (1997) Alternative approaches to the employee-organization relationship: Does investment in employee payoff? Academy of Management Journal 40(5): 1089-1121.

Turnley WH, Feldman DC (2000) Re-examining the effects of psychological contract violations: Unmet expectations and job dissatisfaction as mediators. Journal of Organizational Behavior 21(1): 25-42.

Van Yperen NW, Janssen O (2004) Employees' goal orientations, the quality of leader-member exchange, and the outcomes of job performance and job satisfaction. Academy of Management Journal 47(3): 368-384.

Ware BL (2014) Stop the Gen Y revolving door. Association for talent development. Available at: https://www.td.org/Publications/Magazines/TD/TD-Archive/2014/ 05/Stop-the-Gen-Y-Revolving-Door\#disqus_thread (accessed June 2016). 


\section{Appendix A \\ Psychological Contract Content Items}

\section{Transactional contracts}

I work only hours set out in my contract and no more.

My commitment to this organization is defined by my contract.

My loyalty to the organization is contract specific.

I prefer to work a strictly defined set of working hours.

I only carry out what is necessary to get the job done.

I do not identify with the organization's goals.

I work to achieve the purely short-term goals of my job.

My job means more to me than just a means of paying the bills (R).

It is important to be flexible and to work irregular hours if

necessary (R).

\section{Relational contracts}

I expect to grow in this organization.

I feel part of a team in this organization.

I have a reasonable chance of promotion if I work hard.

To me working for this organization is like being a member of a family.

The organization develops/rewards employees who work hard and exert themselves. I expect to gain promotion in this company with length of service and effort to achieve goals.

I feel this company reciprocates the efforts put in by its employees.

My career path in the organization is clearly mapped out.

I am motivated to contribute 100 percent to this company in return for future employment benefits.

\section{Appendix B \\ Employer/Employee Obligations}

\section{Employer obligations:}

Opportunities for Promotion

High pay

Pay based on current level of performance

Training

Promises of long-term job security

Opportunities for career development

Support with personal problems

\section{Employee obligations}

Work extra hours

Exhibit loyalty to the organization

Volunteer to do non-required tasks on the job

Give advance notice if taking a job elsewhere

Be willing to accept a transfer

Refusal to support/assist the employer's competitors

Protect proprietary information

Spend a minimum of two years in the organization 